\title{
Random fields and apparent exchange bias in the dilute Ising antiferromagnet $\mathrm{Fe}_{0.6} \mathrm{Zn}_{0.4} \mathrm{~F}_{2}$
}

\author{
D. C. Joshi ${ }^{\bowtie}$, P. Nordblad \& R. Mathieu
}

Random field induced spontaneous excess moments appear in field cooled single crystals of diluted Ising antiferromagnets. Here we report results from low temperature measurements of field cooled (including zero field) magnetic hysteresis loops parallel and perpendicular to the $c$-axis of a single crystal of composition $\mathrm{Fe}_{0.6} \mathrm{Zn}_{0.4} \mathrm{~F}_{2}$. We find that weak static ferromagnetic excess moments attained on field cooling give rise to an apparent exchange bias of the magnetic hysteresis loops, whose magnitude is controlled by temperature and the strength and direction of the cooling field. Random field induced temporal excess moments only become observable in cooling fields larger than $1 \mathrm{~T}$ applied along the $c$-axis direction of the $\mathrm{Fe}_{0.6} \mathrm{Zn}_{0.4} \mathrm{~F}_{2}$ single crystal.

The antiferromagnet $\mathrm{FeF}_{2}{ }^{1}$ is a physical realization of a model $3 \mathrm{~d}$ Ising system ${ }^{2}$ as well as an important spintronic material ${ }^{3,4}$. At temperatures below the Néel temperature, $\mathrm{T}_{\mathrm{N}}=78.4 \mathrm{~K}$, of $\mathrm{FeF}_{2}$ an excess magnetic moment develops, that near $\mathrm{T}_{\mathrm{N}}$ decays with a critical exponent characteristic of $3 \mathrm{~d}$ Ising systems ${ }^{5}$. This excess moment gives rise to an apparent exchange bias associated with the vertical shift of the hysteresis loops occurring when cooling the sample through $\mathrm{T}_{\mathrm{N}}$ in a finite magnetic field ${ }^{6}$. The excess moment is rigidly locked to the cooling field direction and is virtually unaffected by any magnetic field changes in the antiferromagnetic state. This is reflected in a field dependent rapidly saturating thermo-remnant magnetization (TRM) and zero isothermal remnant magnetization (IRM) at all accessible fields and temperatures below $\mathrm{T}_{\mathrm{N}}{ }^{6}$. A similar behavior of the TRM and IRM has been observed in antiferromagnetic $\mathrm{Co}_{3} \mathrm{O}_{4}$ nanowires ${ }^{7,8}$, results that are discussed and compared to corresponding results on the dilute antiferromagnet $\mathrm{Fe}_{1-\mathrm{x}} \mathrm{Zn}_{\mathrm{x}} \mathrm{F}_{2}{ }^{9}$.

A dilute Ising antiferromagnet in a homogeneous magnetic field (DAFF) ${ }^{10-12}$ is a replica of the random field Ising model (RFIM) ${ }^{13}$. FeF 2 diluted by diamagnetic dopant $\mathrm{Zn}\left(\mathrm{Fe}_{1-x} \mathrm{Zn}_{x} \mathrm{~F}_{2}(\mathrm{FZF})\right)$ has been extensively used as experimental model systems of a random exchange Ising model (REIM) system in zero applied field and RFIM system in an applied field ${ }^{14-18}$. Measurements of the field and time dependence of the remnant magnetization of FZF ${ }^{18-21}$ have revealed characteristics of RFIM systems superposed on an additional low field static remnant moment comparable to that of $\mathrm{FeF}_{2}$.

In this article, we examine the temperature and field dependence of the parallel and perpendicular magnetization of a $\mathrm{Fe}_{0.6} \mathrm{Zn}_{0.4} \mathrm{~F}_{2}$ single crystal with special emphasis on apparent exchange bias and the effects of random fields by comparing the parallel and the perpendicular magnetization behaviors.

\section{Results and discussion}

Figure 1a shows the temperature dependence of the ZFC parallel and perpendicular susceptibility at different high magnetic fields. The Néel temperature is found at the temperature where $\mathrm{d}(\mathrm{M}(\mathrm{T}) / \mathrm{H}) / \mathrm{dT}$ has a maximum, see Fig. 1b. The observed low field $\mathrm{T}_{\mathrm{N}} \sim 48 \mathrm{~K}$ and the decrease of $\mathrm{T}_{\mathrm{N}}$ with increasing field accords with earlier findings on samples of the same composition ${ }^{22}$. The $\mathrm{H}$ dependence of $\mathrm{T}_{\mathrm{N}}$ stems from the random fields effect induced in $\mathrm{DAFF}^{23}$. It is interesting to note that the differential susceptibility $\left(\Delta \chi=\chi_{\|}-\chi_{\perp}\right)$ has somewhat larger relative amplitude than that of pure $\mathrm{FeF}_{2}$ (see Fig. 7 in Ref. ${ }^{1}$ ) and that the Néel temperature decreases linearly from that of $\mathrm{FeF}_{2}\left(\mathrm{~T}_{\mathrm{N}}=78.4 \mathrm{~K}\right)$ with increasing $x$ as has been observed earlier ${ }^{24,25}$.

Figure $1 \mathrm{c}, \mathrm{d}$ shows the temperature dependence of the low field magnetic susceptibility $\chi=\mathrm{M} / \mathrm{H}$ recorded after $\mathrm{ZFC}$ and $\mathrm{FC}$ protocol in $\mathrm{H}=5 \mathrm{Oe}$ and $100 \mathrm{Oe}$ for two different orientations, parallel (\|c) (Fig. 1c) and perpendicular $(\perp c)$ to the $c$-axis (Fig. 1d) for $\mathrm{Fe}_{0.6} \mathrm{Zn}_{0.4} \mathrm{~F}_{2}$ single crystal. The overall susceptibility $\chi(\mathrm{T})$ behavior at low fields is quite similar to that of the $\mathrm{FeF}_{2}$ single crystal reported in Ref. ${ }^{6}$. The irreversibility between the 

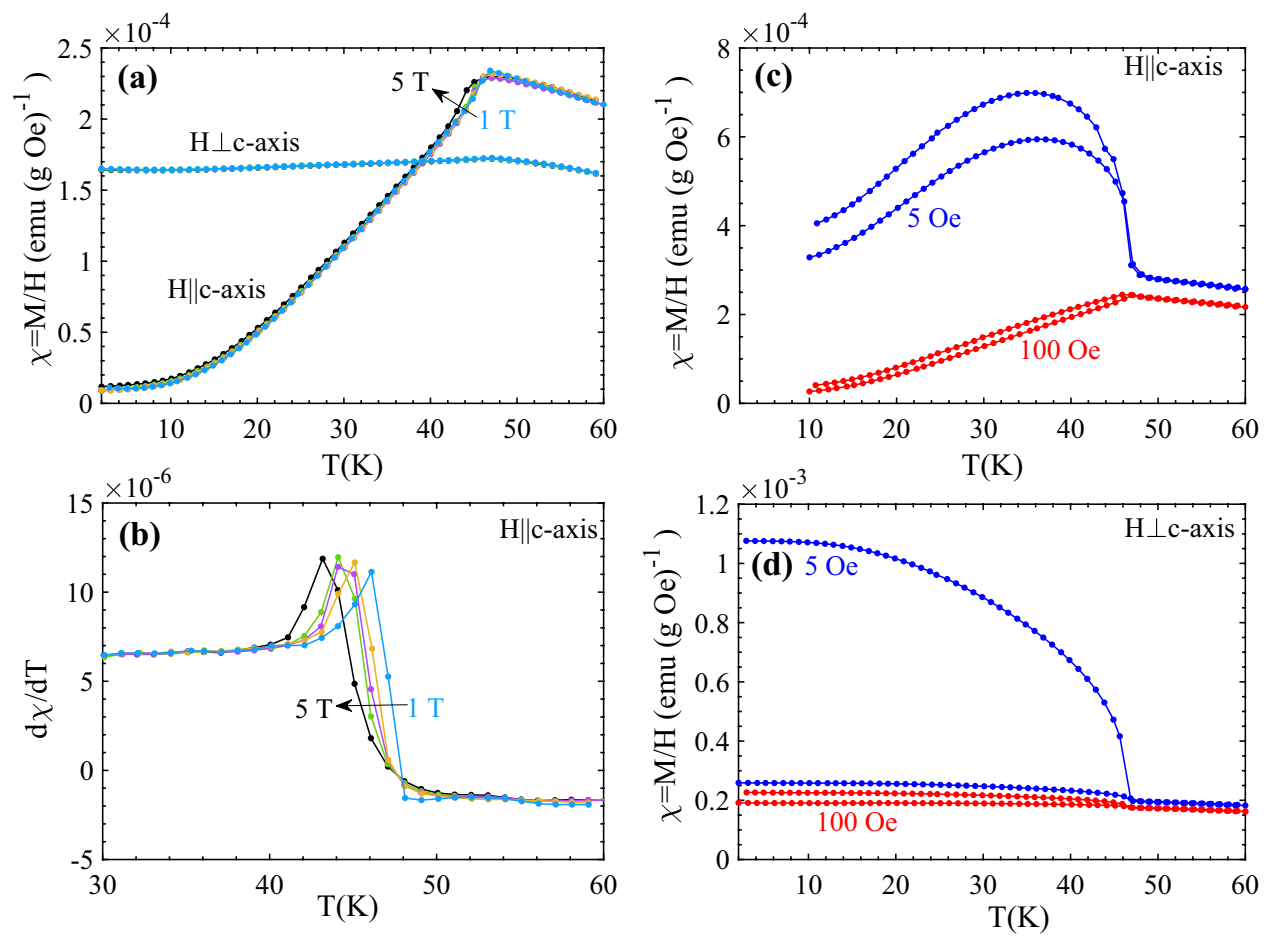

Figure 1. (a) Temperature dependence of magnetic susceptibility $\chi=M / H$ recorded after ZFC, and after FC in higher magnetic fields $(1 \mathrm{~T} \leq \mathrm{H} \leq 5 \mathrm{~T})$ for magnetic fields parallel $(\| c)$ and perpendicular $(\perp c)$ to the $c$-axis of the $\mathrm{Fe}_{0.6} \mathrm{Zn}_{0.4} \mathrm{~F}_{2}$ single crystal. (b) The temperature gradient of susceptibility (d $\chi / \mathrm{dT}$ ) of $\mathrm{ZFC}$ data for $\mathrm{H} \| c$ axis plotted as a function of temperature. (c) and (d) $\mathrm{M}(\mathrm{T}) / \mathrm{H}$ after ZFC (lower curves) and FC (upper curves) the sample to $2 \mathrm{~K}$ recorded in $\mathrm{H}=5 \mathrm{Oe}$ (blue circles) and $\mathrm{H}=100 \mathrm{Oe}$ (red circles) applied parallel (c) and perpendicular (d) to the $c$-axis of the $\mathrm{Fe}_{0.6} \mathrm{Zn}_{0.4} \mathrm{~F}_{2}$ single crystal.
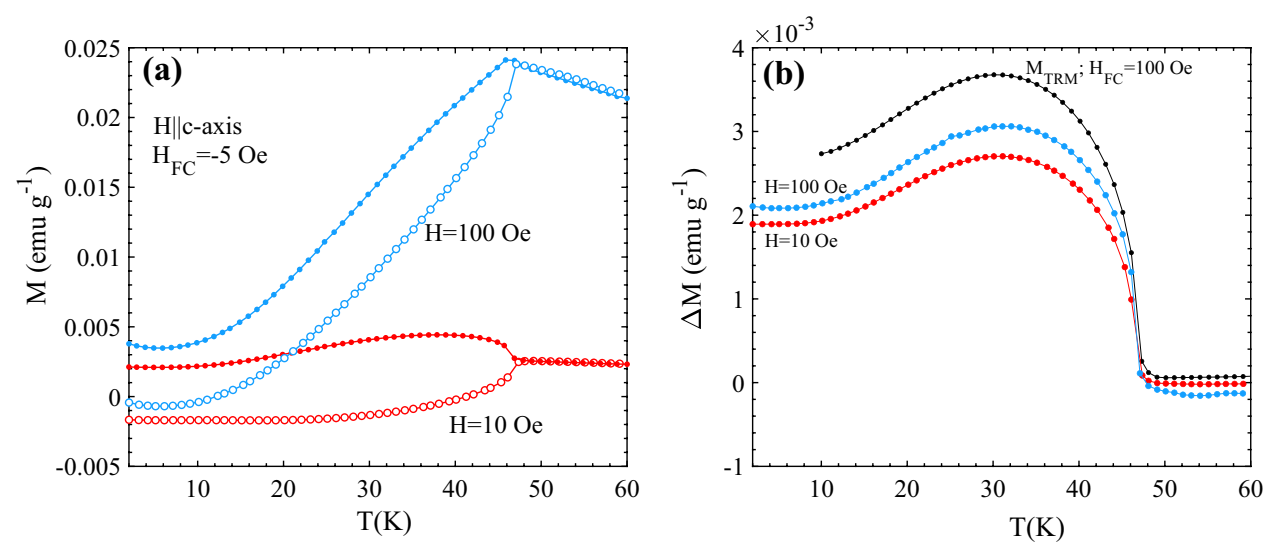

Figure 2. (a) Temperature dependence of the magnetization $\mathrm{M}$ after field cooling in $\mathrm{H}_{\mathrm{FC}}=-5 \mathrm{Oe}\left(\mathrm{M}_{-5 \mathrm{Oe}}\right)$ and recorded in $\mathrm{H}=10$ Oe and 100 Oe during heating (open circles) and cooling (closed circles) for $\mathrm{H} \| c$-axis. (b) Difference between $\mathrm{M}(\mathrm{T})$ recorded in heating $\left(\mathrm{H}_{\mathrm{FC}}=-5 \mathrm{Oe}\right)$ and cooling in $\mathrm{H}=10$ and $100 \mathrm{Oe} ; \Delta \mathrm{M}=\mathrm{M}_{\mathrm{FC}}(\mathrm{T})-$ $\left.\mathrm{M}_{-5 \mathrm{Oe}}(\mathrm{T})\right) / 2$ plotted together with $\mathrm{M}_{\mathrm{TRM}}(\mathrm{T})$ (cooling field $100 \mathrm{Oe}$ ) for $\mathrm{H} \| c$-axis.

ZFC and FC curves below $\mathrm{T}_{\mathrm{N}}$ provides the signature of the excess moments associated with uncompensated antiferromagnetic sub-lattices. In the case of $\mathrm{FeF}_{2}$, the excess moment supposedly arises from a distortion of the antiferromagnetic domain structure of piezo magnetic origin, which also has been suggested as the origin of the low field frozen in excess moments of $\mathrm{FZF}^{19}$.

Even though we have used the ultra-low field option before performing all these measurements, a small stray/remnant field was still present in our experiment. Because of this, the observed ZFC (cooled in a stray magnetic field) curves contain a finite excess moment directed along the stray field (see also Fig. SM7 in supplementary material of Ref. ${ }^{6}$ ). This effect is demonstrated in Fig. 2a, where the temperature dependence of M(T) 

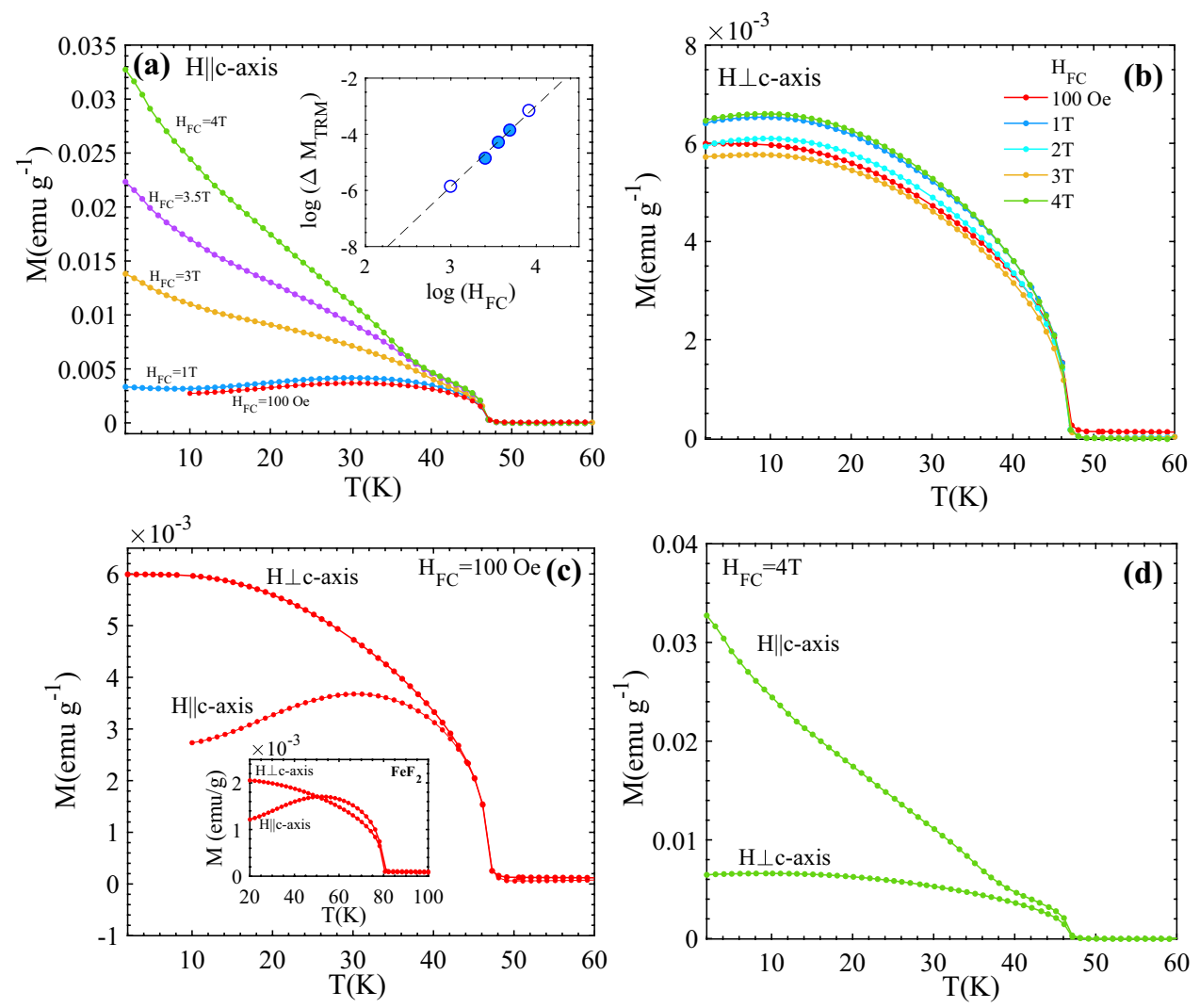

Figure 3. Temperature dependence of thermo-remnant magnetization (TRM) measured along (a) parallel $(\| c)$ and $(\mathbf{b})$ perpendicular $(\perp c)$ to the $c$-axis of the $\mathrm{Fe}_{0.6} \mathrm{Zn}_{0.4} \mathrm{~F}_{2}$ single crystal. The spurious susceptibility contribution to the magnetization due to a weak residual magnetic field in the superconducting magnet has been subtracted from curves. The inset of (a) shows a log-log plot of $\Delta \mathrm{M}_{\mathrm{TRM}}(10 \mathrm{~K})\left(=\mathrm{M}_{\mathrm{TRM}}\left(\mathrm{H}_{\mathrm{FC}}, 10 \mathrm{~K}\right)-\right.$ $\left.\mathrm{M}_{\mathrm{TRM}}(1 \mathrm{~T}, 10 \mathrm{~K})\right)$ vs. $\mathrm{H}_{\mathrm{FC}}$ for $\mathrm{H} \| c$-axis. The solid symbols represent the data points obtained from the main figure $\left(\mathrm{H}_{\mathrm{FC}}=4 \mathrm{~T}, 3.5 \mathrm{~T}\right.$ and $\left.3 \mathrm{~T}\right)$, while the hollow symbols are collected from supplementary Fig. SM4. The dashed line (slope 2.8) is a guide to the eye of the predicted field dependence. (c) and (d) show $\mathrm{M}_{\mathrm{TRM}}(\mathrm{T})$ parallel and perpendicular to the $c$-axis measured after field cooling in $\mathrm{H}_{\mathrm{FC}}=10 \mathrm{mT}(100 \mathrm{Oe})$ and $4 \mathrm{~T}$, respectively. The inset of (c) shows the corresponding curves for $\mathrm{FeF}_{2}$ single crystal $\left(\mathrm{H}_{\mathrm{FC}}=100 \mathrm{Oe}\right.$ (the $\mathrm{H}_{\mathrm{FC}}=4 \mathrm{~T}$ curves are in both directions almost identical to the $\mathrm{H}_{\mathrm{FC}}=100$ Oe curves for $\mathrm{FeF}_{2}$ ).

was recorded after cooling the sample in a low negative magnetic field $\mathrm{H}_{\mathrm{FC}}=-5$ Oe and measured under fields $\mathrm{H}=10 \mathrm{Oe}$ and $100 \mathrm{Oe}$ during the heating and cooling cycle for $\mathrm{H} \| c$-axis. When cooled in - 5 Oe, the excess moment $\left(\mathrm{M}_{\mathrm{exc}}\right)$ is almost saturated and directed in the negative magnetization direction. Applying a positive field does not change the direction of $\mathrm{M}_{\text {exc }}$. Thus, in the $\mathrm{M}(\mathrm{T})$ experiments on increasing temperature, the measured $\mathrm{M}_{\mathrm{FC}}(\mathrm{T})=\chi_{\|} \mathrm{H}+\mathrm{M}_{\text {exc }}(\mathrm{T})$ in the $\mathrm{FC}$ case and $\mathrm{M}_{-5 \mathrm{Oe}}(\mathrm{T})=\chi_{\|}(\mathrm{T}) \mathrm{H}-\mathrm{M}_{\text {exc }}(\mathrm{T})$ when cooled in -5 Oe. The difference between the cooling and heating curve at a particular temperature is then equal to $2 \times \mathrm{M}_{\text {exc }}(\mathrm{T})$. This is demonstrated in Fig. 2b, where $\left(\mathrm{M}_{\mathrm{FC}}(\mathrm{T})-\mathrm{M}_{-5 \mathrm{Oe}}(\mathrm{T})\right) / 2$ is plotted together with the measured $\mathrm{M}_{\mathrm{TRM}}(\mathrm{T})$ after FC in 100 Oe. The somewhat smaller magnitude of the derived $\mathrm{M}_{\text {exc }}(\mathrm{T})$ compared to $\mathrm{M}_{\mathrm{TRM}}(\mathrm{T})$ is due to the fact that the excess moment is only almost saturated when field cooling in -5 Oe.

The signatures of random fields are observed in the temperature dependence of thermo-remnant magnetization $\mathrm{M}_{\mathrm{TRM}}(\mathrm{T})$. The $\mathrm{M}_{\mathrm{TRM}}(\mathrm{T})$ curve for $\mathrm{H}(\geq 1 \mathrm{~T})$ applied along the $c$-axis $(\mathrm{H} \| c$-axis) shows a continuous non-linear increase at low temperatures $\left(\mathrm{T}<\mathrm{T}_{\mathrm{N}}\right)$ due to cumulative effect of low field static excess moments and random field induced remnant moments (Fig. 3a). Whereas, for low fields $(\mathrm{H}=100 \mathrm{Oe})$ and for all fields in the case of $\mathrm{H} \perp c$-axis only the saturated static excess moment is observed and $\mathrm{M}_{\mathrm{TRM}}(\mathrm{T})$ curves (Fig. 3a-c) are quite similar to the corresponding curves of $\mathrm{FeF}_{2}$ (inset of $\left.3 \mathrm{c}\right)^{6}$. See supplementary Fig. SM2 for $\mathrm{M}_{\mathrm{TRM}}(\mathrm{T})$ curves represented in $\mu_{\mathrm{B}} / \mathrm{Fe}$ for two selected $\mathrm{H}_{\mathrm{FC}}=10 \mathrm{mT}$ and $4 \mathrm{~T}$. A comparison of $\mathrm{M}_{\mathrm{TRM}}$ curves for both orientations under $\mathrm{H}_{\mathrm{FC}}=4 \mathrm{~T}$ are shown in Fig. 3d. The logarithmic dependence of $\Delta \mathrm{M}_{\mathrm{TRM}}\left(=\mathrm{M}_{\mathrm{TRM}}\left(\mathrm{H}_{\mathrm{FC}}, 10 \mathrm{~K}\right)-\mathrm{M}_{\mathrm{TRM}}\left(\mathrm{H}_{\mathrm{FC}}=1 \mathrm{~T}, 10 \mathrm{~K}\right)\right)$ on $\log \left(\mathrm{H}_{\mathrm{FC}}\right)$ for $\mathrm{H} \| c$-axis (shown in the inset of Fig. 3a) follows a linear behavior with a slope of $\sim 2.8$, which is in agreement with the predicted behavior due to random field effects and in agreement with earlier findings ${ }^{18}$.

Figure 4a shows the $\mathrm{M}(\mathrm{H})$ curves recorded at $\mathrm{T}=10 \mathrm{~K}$ with field sweep $0 \rightarrow+1 \mathrm{~T} \rightarrow-1 \mathrm{~T} \rightarrow+1 \mathrm{~T}$ after ZFC for $\mathrm{H} \| c$-axis and $\mathrm{H} \perp c$-axis. A shift in the hysteresis loops (apparent exchange bias ${ }^{6}$ ) is observed for both orientations when the sample is cooled from $\mathrm{T}=60 \mathrm{~K}$ to $\mathrm{T}=10 \mathrm{~K}$ in $\mathrm{H}_{\mathrm{FC}}=100 \mathrm{Oe}$ as shown in Fig. $4 \mathrm{~b}$. The observed shift $\left|\mathrm{H}_{\mathrm{EB}}\right|$ is $36 \mathrm{Oe}$ and $170 \mathrm{Oe}$ for $\perp \mathrm{c}$ and $\| \mathrm{c}$ orientations, respectively. The effect of temperature on the $\mathrm{FC} \mathrm{M}(\mathrm{H})$ curves are shown in Fig. 5. The $\mathrm{M}(\mathrm{H})$ curves are recorded after $\mathrm{FC}$ in $\mathrm{H}_{\mathrm{FC}}=100$ Oe from $60 \mathrm{~K}$ down 

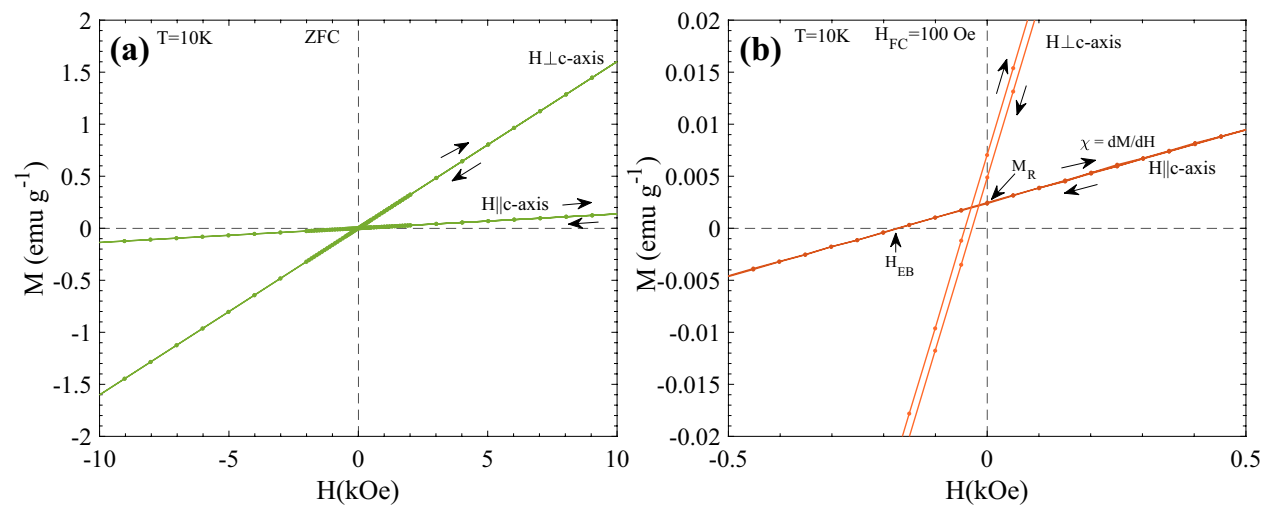

Figure 4. (a) the field dependence of magnetization $\mathrm{M}(\mathrm{H})$ curves recorded with (a) field sweep $0 \rightarrow+1 \mathrm{~T} \rightarrow-1 \mathrm{~T} \rightarrow+1 \mathrm{~T}$ after $\mathrm{ZFC}$ from $60 \mathrm{~K}$ down to $10 \mathrm{~K}$, for two different orientations. (b) $\mathrm{M}(\mathrm{H})$ recorded with field sweep $100 \mathrm{Oe} \rightarrow+1 \mathrm{~T} \rightarrow-1 \mathrm{~T} \rightarrow+1 \mathrm{~T}$ after FC in $100 \mathrm{Oe}$ from $60 \mathrm{~K}$ down to $10 \mathrm{~K}$. The parameters $\mathrm{H}_{\mathrm{EB}}, \mathrm{M}_{\mathrm{R}}$, and $\chi$ are indicated in $(\mathbf{b})$. The weak $(\sim 5 \mathrm{Oe})$ reversed coercivity observable for the $\mathrm{H} \perp c$ loop is an artefact due to the field history dependent residual field in the superconducting magnet of the MPMS SQUID magnetometer-the same coercivity artefact is seen also in the zoomed $\mathrm{M}$ vs $\mathrm{H}$ curves in Fig. 5.
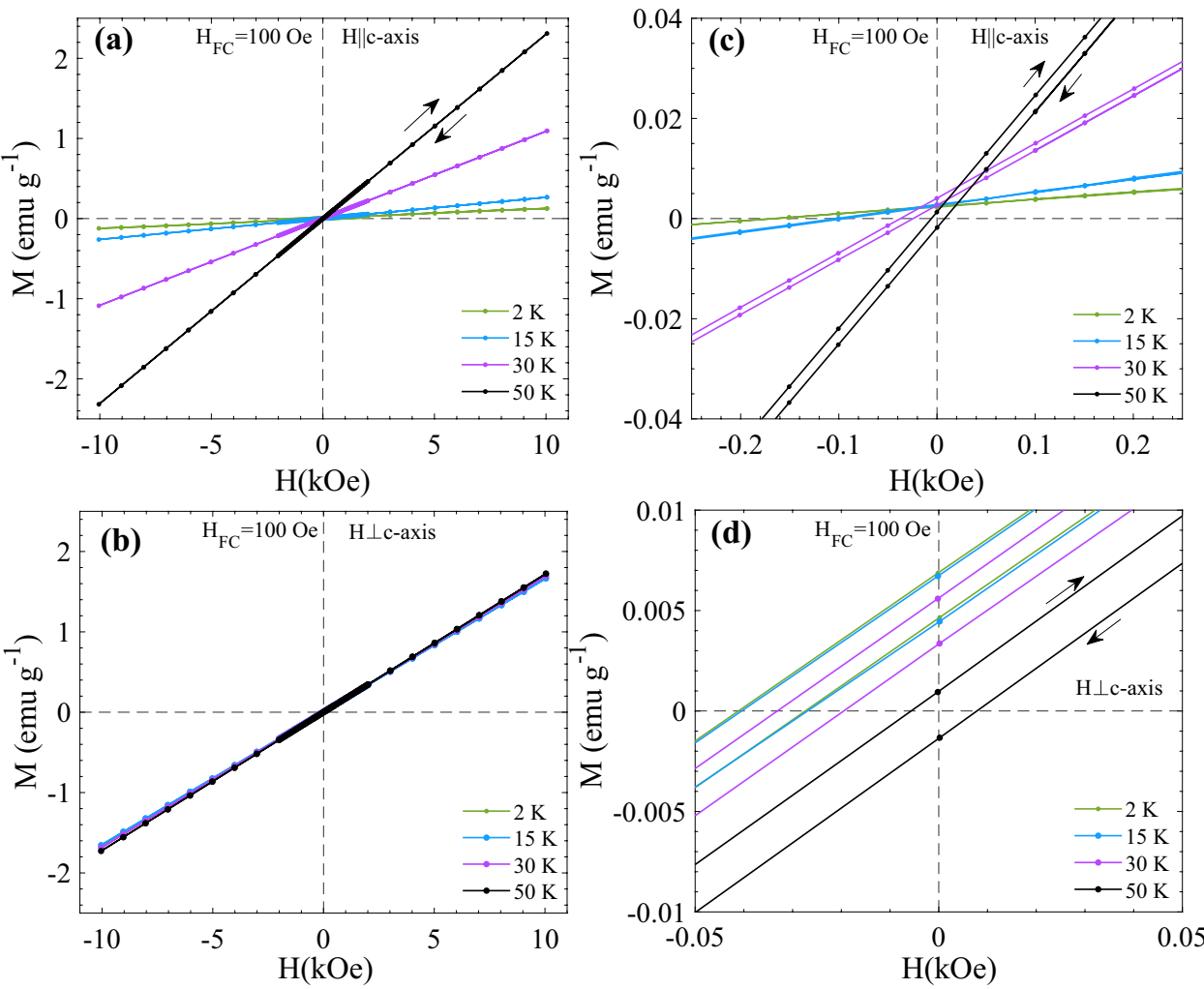

Figure 5. $\mathrm{M}(\mathrm{H})$ curves recorded with field sweep $100 \mathrm{Oe} \rightarrow+1 \mathrm{~T} \rightarrow-1 \mathrm{~T} \rightarrow+1 \mathrm{~T}$ after $\mathrm{FC}$ in 100 Oe from $60 \mathrm{~K}$ down to different temperatures, for $(\mathbf{a}) \mathrm{H} \| c$-axis and (b) $\mathrm{H} \perp c$-axis. $(\mathbf{c})$ and $(\mathbf{d})$ are zoomed views of $(\mathbf{a})$ and (b), respectively.

to different temperatures with field sweep $100 \mathrm{Oe} \rightarrow+1 \mathrm{~T} \rightarrow-1 \mathrm{~T} \rightarrow+1 \mathrm{~T}$. Zoomed views of the $\mathrm{M}(\mathrm{H})$ curves at low fields are shown in Fig. $5 \mathrm{c}, \mathrm{d}$. A significant decrease in the slope $\chi=\mathrm{dM} / \mathrm{dH}$ and increase in the apparent exchange bias $\mathrm{H}_{\mathrm{EB}}$ are observed as the measuring temperature decreases from $\mathrm{T}=60 \mathrm{~K} \rightarrow 2 \mathrm{~K}$, for $\mathrm{H} \| c$-axis. However, for $\mathrm{H} \perp c$-axis, these changes are very subtle as compared to $\mathrm{H} \| c$-axis. In Fig. $6 \mathrm{M}(\mathrm{H})$ curves recorded after cooling the sample form $60 \mathrm{~K}$ to $2 \mathrm{~K}$ under different cooling fields with field sweep $+\mathrm{H}_{\mathrm{FC}} \rightarrow 5 \mathrm{~T} \rightarrow-5 \mathrm{~T} \rightarrow$ $5 \mathrm{~T}$ are shown for (a) $\mathrm{H} \| c$-axis and (b) $\mathrm{H} \perp c$-axis (see supplementary Fig. SM4 for the corresponding $\mathrm{T}=10 \mathrm{~K}$ data). In contrast to $\mathrm{H} \perp c$-axis, $\mathrm{M}(\mathrm{H})$ curves for $\mathrm{H} \| c$-axis show non-linear asymmetric behavior. This behavior becomes more prominent with increasing $\mathrm{H}_{\mathrm{FC}}$ and decreasing $\mathrm{T}$. This trend can be clearly noticed from the absolute value of $\mathrm{M}$ at maximum fields $( \pm 5 \mathrm{~T})$ for $\mathrm{T}=2 \mathrm{~K}$ and $10 \mathrm{~K}$ (see inset of supplementary Fig. SM4b). The 

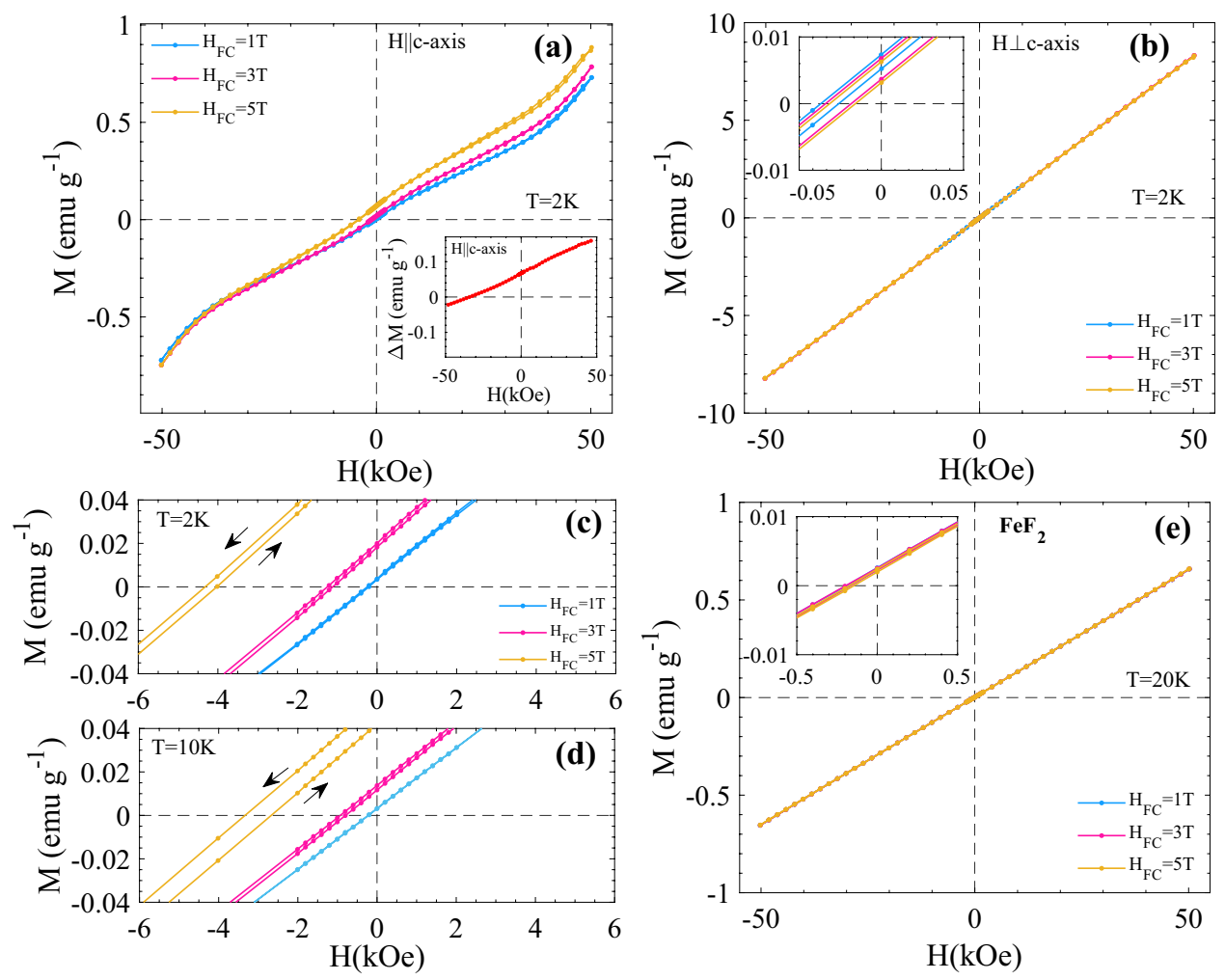

Figure 6. $\mathrm{M}(\mathrm{H})$ recorded after $\mathrm{FC}$ with field sweep $+\mathrm{H}_{\mathrm{FC}} \rightarrow 5 \mathrm{~T} \rightarrow-5 \mathrm{~T} \rightarrow 5 \mathrm{~T}$ from $60 \mathrm{~K}$ down to $\mathrm{T}=2 \mathrm{~K}$ for (a) $\mathrm{H} \| c$-axis and (b) $\mathrm{H} \perp c$-axis. Inset of (a) shows the $\mathrm{H}$ dependence of difference between the $\mathrm{M}(\mathrm{H})$ curves measured after field cooling in $\mathrm{H}_{\mathrm{FC}}=5 \mathrm{~T}$ and after $\mathrm{H}_{\mathrm{FC}}=1 \mathrm{~T}$ for $\mathrm{H} \| c$-axis. Inset of $(\mathbf{b})$ shows the zoomed view of main panel loops. (c) and (d) shows the zoomed view of $\mathrm{M}(\mathrm{H})$ loops with field sweep $+\mathrm{H}_{\mathrm{FC}} \rightarrow 5 \mathrm{~T} \rightarrow-5 \mathrm{~T} \rightarrow 5 \mathrm{~T}$ after field cooling from $\mathrm{T}=60 \mathrm{~K}$ to $2 \mathrm{~K}$ and $10 \mathrm{~K}$, respectively (see supplementary Fig. SM4 for full $\mathrm{M}(\mathrm{H}$ ) curves). (e) $\mathrm{M}(\mathrm{H})$ loops with field sweep $+\mathrm{H}_{\mathrm{FC}} \rightarrow 5 \mathrm{~T} \rightarrow-5 \mathrm{~T} \rightarrow 5 \mathrm{~T}$ measured $\| c$-axis after field cooling from $\mathrm{T}=100 \mathrm{~K}$ to $\mathrm{T}=20 \mathrm{~K}$ for an $\mathrm{FeF}_{2}$ single crystal.

difference plot of the $\mathrm{M}(\mathrm{H})$ curves recorded after $\mathrm{FC}$ in $\mathrm{H}_{\mathrm{FC}}=5 \mathrm{~T}$ and $\mathrm{H}_{\mathrm{FC}}=1 \mathrm{~T}\left(\Delta \mathrm{M}=\mathrm{M}\left(\mathrm{H}_{\mathrm{FC}}=5 \mathrm{~T}, \mathrm{H}\right)-\mathrm{M}\left(\mathrm{H}_{\mathrm{FC}}\right.\right.$ $=1 \mathrm{~T}, \mathrm{H})$ ) shown in inset of Fig. $6 \mathrm{a}$ confirm the upward shift of the $5 \mathrm{~T}$ curve, compared to the $1 \mathrm{~T}$ curve, due to random field induced excess moments. Interestingly, it also implies an enhanced overall response to magnetic field changes of the sample when cooled in $5 \mathrm{~T}$, compared to the $\mathrm{M}$ vs $\mathrm{H}$ curve of the sample when cooled in a lower field (1 T), where random field induced excess moments are hidden by the larger static excess moments. Another observation is that temperature dependent relaxation effects yield intrinsic coercivity changes with increasing $\mathrm{H}_{\mathrm{FC}}$, as illustrated in Fig. $6 \mathrm{c}$, d (note the direction of the arrows marking the magnetic field sweeps in those panels in comparison to the low-field results presented in Fig. 4). The observed temporal intrinsic coercivity $\mathrm{H}_{\mathrm{C}}$ is 330 and $140 \mathrm{Oe}$ at $10 \mathrm{~K}$ and $2 \mathrm{~K}$, respectively, for $\mathrm{H}_{\mathrm{FC}}=5 \mathrm{~T}$. Whereas, the small spurious coercivity noticed in $\mathrm{ZFC}$ and $\mathrm{H}_{\mathrm{FC}}=1 \mathrm{~T} \mathrm{M}(\mathrm{H})$ curves is associated with the artifact due to the field history dependent residual field in the superconducting magnet of the SQUID magnetometer (see Fig. 4 and supplementary Fig. SM5). Neither non-linearities nor intrinsic coercivity enhancement is observed in undoped $\mathrm{FeF}_{2}$ in the same magnetic field range, as illustrated in Fig. 6e. The results of ZFC M vs. $\mathrm{H}$ measurements $\mathrm{H} \| c$-axis up to fields of $18 \mathrm{~T}$ on $\mathrm{Fe}_{0.6} \mathrm{Zn}_{0.4} \mathrm{~F}_{2}{ }^{22}$ indicate that the hysteresis properties of a sample that has been field cooled in very high magnetic field (e.g. $18 \mathrm{~T}$ ) should show interesting new features compared to the ZFC sample.

The linear $\mathrm{M}$ vs $\mathrm{H}$ curves observed for fields $\mathrm{H} \perp c$-axis and low fields $\mathrm{H} \| c$-axis can be described by the equation: $\mathrm{M}=\chi \mathrm{H}+\mathrm{M}_{\mathrm{R}}$, yielding $\mathrm{H}_{\mathrm{EB}}=-\mathrm{M}_{\mathrm{R}} / \chi$ at $\mathrm{M}=0$. For comparison to this simple description, the parameters $\mathrm{H}_{\mathrm{EB}}, \mathrm{M}_{\mathrm{R}}$ and $\chi$ (inset) extracted from Figs. 5 and 6 are plotted in Fig. 7 for both $\mathrm{H} \|$ - and $\perp c$-axis. The behavior of $\mathrm{M}_{\mathrm{R}} / \chi$ is consistent with the observed values of the apparent $\mathrm{H}_{\mathrm{EB}}$. For $\mathrm{H} \| c$-axis the $\mathrm{M}_{\mathrm{R}}$ dependence at higher cooling fields accords with that predicted for RFIM systems ${ }^{18}$. As seen in Fig. $7 \mathrm{~b}, \mathrm{H}_{\mathrm{EB}}$ value approaches $\sim 5 \mathrm{kOe}$ at $2 \mathrm{~K}\left(\mathrm{H}_{\mathrm{FC}}=5 \mathrm{~T}\right)$. These observations are summarized in Fig. 8. Figure 8 shows the temperature dependence of the ratio of $\mathrm{M}_{\mathrm{TRM}}\left(\mathrm{H}_{\mathrm{FC}}\right)$ (from Fig. 3a) divided by the susceptibility $\mathrm{M}_{\mathrm{FC}} / \mathrm{H}$ recorded at $\mathrm{H}=1 \mathrm{~T}$ (Fig. 1a) for $\mathrm{H}|| c$-axis. For comparison $\left|\mathrm{H}_{\mathrm{EB}}\right|$ determined from the $\mathrm{M}(\mathrm{H})$ curves (Fig. 6a and supplementary Fig. SM4a) is shown by square symbols. The inset shows a comparison of $\mathrm{M}_{\mathrm{TRM}} /\left(\mathrm{M}_{\mathrm{FC}} / \mathrm{H}\right),\left|\mathrm{H}_{\mathrm{EB}}\right|$ and $\mathrm{M}_{\mathrm{R}} / \chi$ for $\mathrm{H}_{\mathrm{FC}}=100$ Oe. 

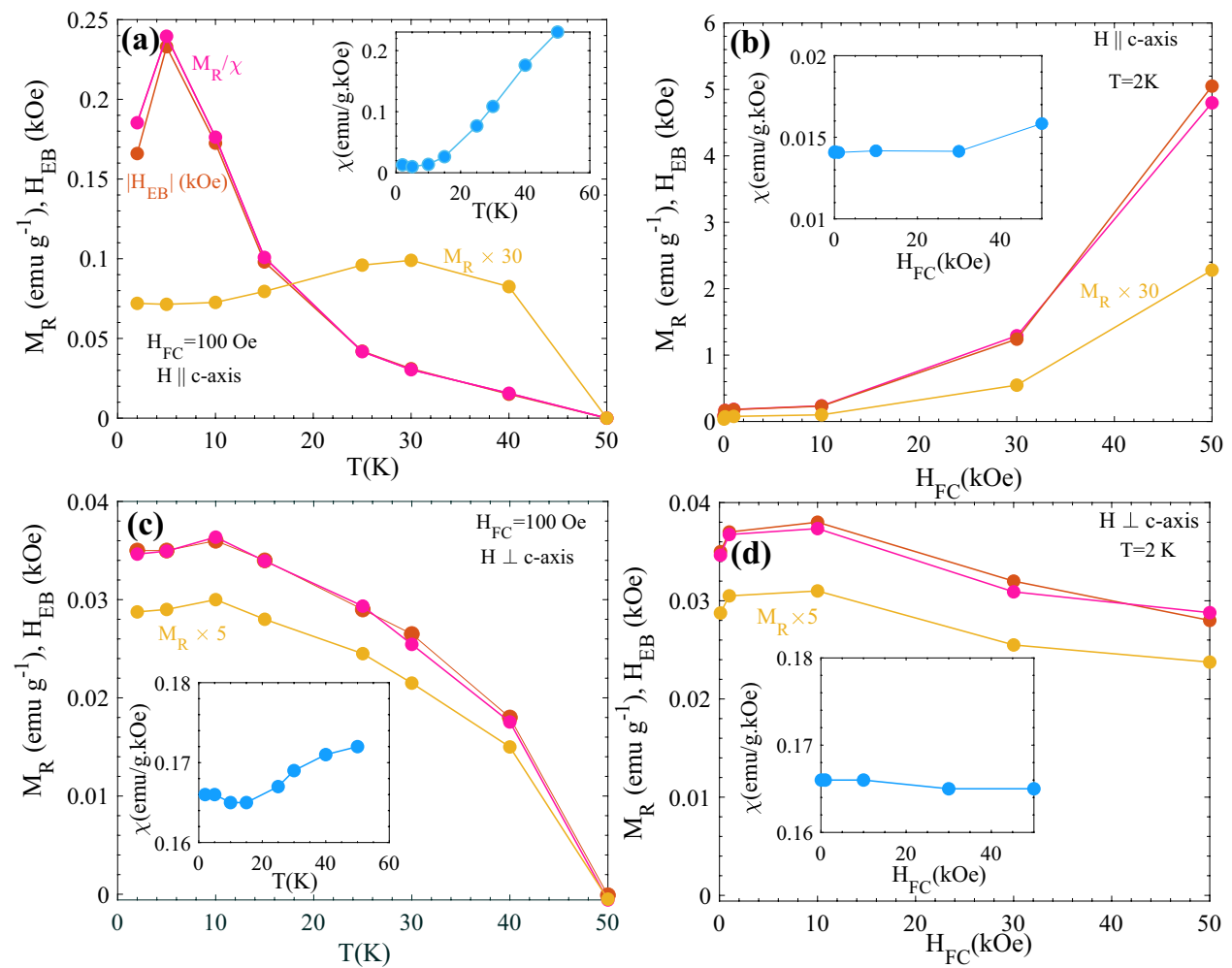

Figure 7. Variation of $\left|\mathrm{H}_{\mathrm{EB}}\right|, \mathrm{M}_{\mathrm{R}} / \chi$ and $\mathrm{M}_{\mathrm{R}}$, determined from Fig. 5 and 6 for (a,b) $\mathrm{H} \| c$-axis and (c,d) $\mathrm{H} \perp c$-axis as a function of the $(\mathbf{a}-\mathbf{c})$ temperature and $(\mathbf{b}-\mathbf{d}) \mathrm{H}_{\mathrm{FC}}$. The insets show the corresponding variation of $\chi=\mathrm{dM} /$ $\mathrm{dH}$ (in (b), where the $\mathrm{M}$ vs $\mathrm{H}$ loops are non-linear (Fig. 6a) at higher fields, $\chi$ is defined from $\left.(\mathrm{dM} / \mathrm{dH})_{\mathrm{H}=0}\right)$.

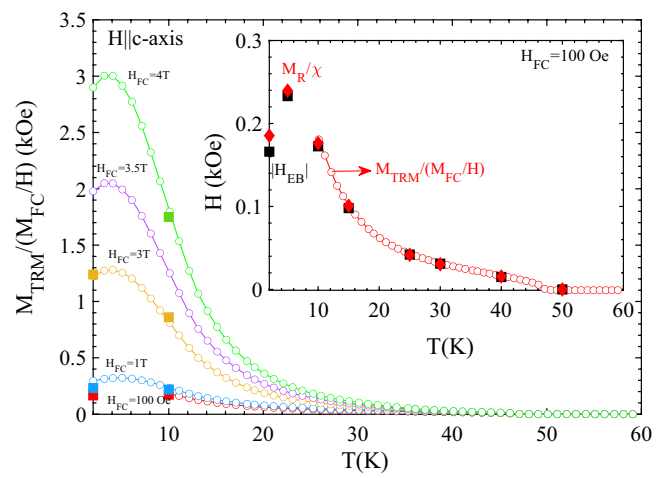

Figure 8. Temperature dependence of the ratio of $\mathrm{M}_{\mathrm{TRM}}\left(\mathrm{H}_{\mathrm{FC}}\right)$ (from Fig. 3a) divided by the susceptibility $\mathrm{M}_{\mathrm{FC}} / \mathrm{H}$ recorded at $\mathrm{H}=1 \mathrm{~T}$ (Fig. 1a) for $\mathrm{H}|| c$-axis. For comparison $\left|\mathrm{H}_{\mathrm{EB}}\right|$ determined from the $\mathrm{M}(\mathrm{H})$ curves (Fig. 6a and supplementary Fig. SM4a) is shown by square symbols. Inset shows $M_{T R M} /\left(M_{F C} / H\right)$ (open red circles), $\left|\mathrm{H}_{\mathrm{EB}}\right|$ (solid black squares) and $\mathrm{M}_{\mathrm{R}} / \chi$ (solid red prisms) for $\mathrm{H}_{\mathrm{FC}}=100$ Oe (cf. Fig. 7a).

\section{Conclusions}

The field and temperature dependence of the magnetization measured parallel and perpendicular to the $c$-axis of the dilute Ising antiferromagnet $\mathrm{Fe}_{0.6} \mathrm{Zn}_{0.4} \mathrm{~F}_{2}$ reveal apparent exchange bias effects governed by static excess moments, which at higher fields in the case of $\mathrm{H} \| c$-axis are enhanced by random field induced temporal excess moments. $\mathrm{H}_{\mathrm{EB}}$ amounts to $\sim 5 \mathrm{kOe}$ at $2 \mathrm{~K}\left(\mathrm{H}_{\mathrm{FC}}=5 \mathrm{~T}\right)$. The observed hysteresis behavior with field $\mathrm{H} \perp c$-axis and at low fields $\mathrm{H} \| c$-axis is similar to that observed in $\mathrm{FeF}_{2}{ }^{6}$, indicating that the origin of static excess moments is the same in pure and diluted samples. Irrespective of origin of the excess moments, the vertical shift (apparent exchange bias) of the hysteresis curves is directly reflected in the field dependence of the TRM(H) and IRM(H) curves $^{7-9}$; where IRM $(\mathrm{H})=0$ at all accessible field, i.e. no remnant magnetization is attained on a zero field cooled sample. Systems with such properties exhibit magnetic hysteresis curves with apparent exchange bias that are fully controlled by the cooling field and the measurement temperature. The temporal excess moment give rise to cooling field and field sweep rate dependent intrinsic coercivity that of the order of $\sim 330$ Oe at $10 \mathrm{~K}$. 


\section{Methods}

The temperature and field dependent magnetization measurements for $\mathrm{Fe}_{0.6} \mathrm{Zn}_{0.4} \mathrm{~F}_{2}$ single crystal were performed using a superconducting quantum interference device (SQUID) magnetometer from Quantum Design Inc. (Model: XL). The same single crystal was used in Ref. ${ }^{5}$. The magnetic field $\mathrm{H}$ was applied along two different orientations of the single crystal $(i)$ parallel to the $c$-axis $(\mathrm{H} \| c$-axis) and (ii) perpendicular to the $c$-axis $(\mathrm{H} \perp c$ axis). The temperature dependence of the magnetization $\mathrm{M}(\mathrm{T})$ was recorded in zero field cooled (ZFC) and field cooled (FC) conditions in different magnetic fields. The thermo-remnant magnetization (TRM) was recorded on warming in zero magnetic field, after cooling the sample from $60 \mathrm{~K}$ down to $2 \mathrm{~K}$ in presence of an applied magnetic field. The schematic of $\mathrm{M}(\mathrm{T})$ measurement is shown in supplementary Fig. SM1. The field dependence of the magnetization $\mathrm{M}(\mathrm{H})$ was recorded at a temperature $\mathrm{T}$ after zero-field cooling from $60 \mathrm{~K}$ down to low temperatures ( $\mathrm{ZFC} \mathrm{M}(\mathrm{H})$ ) and after field cooling in $\mathrm{H}_{\mathrm{FC}}(\mathrm{FC} \mathrm{M}(\mathrm{H})$ ). For the $\mathrm{FC} \mathrm{M}(\mathrm{H})$ measurements, the field is increased from $\mathrm{H}_{\mathrm{FC}}$ to the maximum field $\left(\mathrm{H}_{\max }\right)$ then decreased to $-\mathrm{H}_{\max }$ and finally increased back to $\mathrm{H}_{\max }$. Before performing all of the ZFC or FC measurements with $\mathrm{H}_{\mathrm{FC}} \leq 100 \mathrm{Oe}$, the background magnetic field of the magnet was reset to zero by using the ultra-low field option.

Received: 22 June 2020; Accepted: 17 August 2020

Published online: 03 September 2020

\section{References}

1. Stout, J. W. \& Matarrese, L. M. Magnetic anisotropy of the iron-group fluorides. Rev. Mod. Phys. 25, 338-343 (1953).

2. Belanger, D. P. et al. Critical behavior in anisotropic antiferromagnets. J. Magn. Magn. Mater. 31-34, 1095-1096 (1983)

3. Baltz, V. et al. Antiferromagnetic spintronics. Rev. Mod. Phys. 90, 15005 (2018).

4. Nogués, J., Moran, T. J., Lederman, D., Schuller, I. K. \& Rao, K. V. Role of interfacial structure on exchange-biased FeF $2-$ Fe. Phys. Rev. B 59, 6984 (1999)

5. Mattsson, J., Djurberg, C. \& Nordblad, P. Determination of the critical exponent $\beta$ from measurements of a weak spontaneous magnetisation in the 3d Ising antiferromagnet $\mathrm{FeF}_{2}$. J. Magn. Magn. Mater. 136, 23-28 (1994).

6. Joshi, D. C., Nordblad, P. \& Mathieu, R. Ferromagnetic excess moments and apparent exchange bias in FeF $F_{2}$ single crystals. Sci. Rep. 9, 1-6 (2019).

7. Benitez, M. J., Petracic, O., Tüysüz, H., Schüth, F. \& Zabel, H. Fingerprinting the magnetic behavior of antiferromagnetic nanostructures using remanent magnetization curves. Phys. Rev. B 83, 134424 (2011).

8. Benitez, M. J. et al. Evidence for core-shell magnetic behavior in antiferromagnetic $\mathrm{Co}_{3} \mathrm{O}_{4}$ nanowires. Phys. Rev. Lett. 101, 97206 (2008).

9. Montenegro, F. C., Rezende, S. M. \& Coutinho-Filho, M. D. Random field to spin glass crossover behavior in the random magnet $\mathrm{Fe}_{\mathrm{x}} \mathrm{Zn}_{1-\mathrm{x}} \mathrm{F}_{2}$. Rev. Bras. Fis. 21, 192 (1991).

10. Fishman, S. \& Aharony, A. Random field effects in disordered anisotropic antiferromagnets. J. Phys. C Solid State Phys. 12, L729 (1979).

11. Cardy, J. L. Random-field effects in site-disordered Ising antiferromagnets. Phys. Rev. B 29, 505 (1984).

12. Binek, C., Kuttler, S. \& Kleemann, W. Magnetic-field-induced griffiths phase versus random-field criticality and domain wall susceptibility of $\mathrm{Fe}_{0.47} \mathrm{Zn}_{0.53} \mathrm{~F}_{2}$. Phys. Rev. Lett. 75, 2412 (1995).

13. Imry, Y. \& Ma, S. K. Random-field instability of the ordered state of continuous symmetry. Phys. Rev. Lett. 35, 1399 (1975).

14. Jaccarino, V. \& King, A. R. Static and dynamic critical-behavior in random magnets. J. Phys. 49, 1209-1214 (1988).

15. Belanger, D. P. \& Young, A. P. The random field ising model. J. Magn. Magn. Mater. 100, 272-291 (1991).

16. Belanger, D. P. Experimental characterization of the Ising model in disordered antiferromagnets. Braz. J. Phys. 30, 682-692 (2000).

17. Kleemann, W., King, A. R. \& Jaccarino, V. Critical behavior of the magnetization of a d= 3 random-field Ising system. Phys. Rev. B 34, 479 (1986).

18. Mattsson, J., Djurberg, C. \& Nordblad, P. Low-temperature magnetization in dilute Ising antiferromagnets. Phys. Rev. B 61, 11274 (2000).

19. Kushauer, J., Binek, C. \& Kleemann, W. Blocking of logarithmic temporal relaxation of magnetic remanence by piezomagnetically induced domains in $\mathrm{Fe}_{1-\mathrm{x}} \mathrm{Zn}_{\mathrm{x}} \mathrm{F}_{2}$. J. Appl. Phys. 75, 5856-5858 (1994).

20. Lederman, M., Hammann, J. \& Orbach, R. Net spontaneous magnetisation in the dilute ising antiferromagnet $\mathrm{Fe}_{0.46} \mathrm{Zn}_{0.54} \mathrm{~F}_{2}$. Phys. B Condens. Matter 165, 179-180 (1990).

21. Kushauer, J., Kleemann, W., Mattsson, J. \& Nordblad, P. Crossover from logarithmically relaxing to piezomagnetically frozen magnetic remanence in low-field-cooled $\mathrm{Fe}_{0.47} \mathrm{Zn}_{0.53} \mathrm{~F}_{2}$. Phys. Rev. B 49, 6346 (1994).

22. Montenegro, F. C., Lima, K. A., Torikachvili, M. S. \& Lacerda, A. H. Phase diagram of the random-field Ising system Fe ${ }_{0.60} \mathrm{Zn}_{0.40} \mathrm{~F}_{2}$ at intense fields. J. Magn. Magn. Mater. 177, 145-146 (1998).

23. Lederman, M., Selinger, J. V., Bruinsma, R., Orbach, R. \& Hammann, J. Dynamics of the diluted Ising antiferromagnet Fe ${ }_{0.46} \mathrm{Zn}_{0.54} \mathrm{~F}_{2}$ in the (H, T) plane. Phys. Rev. B 48, 3810 (1993).

24. Raposo, E. P., Coutinho-Filho, M. D. \& Montenegro, F. C. Influence of frustration on ad $=3$ diluted antiferromagnet: Fe $\mathrm{Zn}_{1-\mathrm{x}} \mathrm{F}_{2}$. J. Magn. Magn. Mater. 154, L155-L159 (1996).

25. Sousa, L. L. L., Araújo, L. R. S., Machado, F. L. A., Montenegro, F. C. \& Rezende, S. M. Specific heat of the dilute antiferromagnetic system $\mathrm{Fe}_{x} \mathrm{Zn}_{1-x} \mathrm{~F}_{2}$. J. Phys. Conf. Ser. 200, 32069 (2010).

\section{Acknowledgments}

We thank the Stiftelsen Olle Engkvist Byggmästare and the Swedish Research Council (VR) for financially supporting this work.

\section{Author contributions}

D.C.J., P.N., and R.M. planned and performed the experiments and jointly wrote the final manuscript.

\section{Funding}

Open Access funding provided by Uppsala University. 


\section{Competing interests}

The authors declare no competing interests.

\section{Additional information}

Supplementary information is available for this paper at https://doi.org/10.1038/s41598-020-71533-6.

Correspondence and requests for materials should be addressed to D.C.J.

Reprints and permissions information is available at www.nature.com/reprints.

Publisher's note Springer Nature remains neutral with regard to jurisdictional claims in published maps and institutional affiliations.

(c) (i) Open Access This article is licensed under a Creative Commons Attribution 4.0 International cc) License, which permits use, sharing, adaptation, distribution and reproduction in any medium or format, as long as you give appropriate credit to the original author(s) and the source, provide a link to the Creative Commons licence, and indicate if changes were made. The images or other third party material in this article are included in the article's Creative Commons licence, unless indicated otherwise in a credit line to the material. If material is not included in the article's Creative Commons licence and your intended use is not permitted by statutory regulation or exceeds the permitted use, you will need to obtain permission directly from the copyright holder. To view a copy of this licence, visit http://creativecommons.org/licenses/by/4.0/.

(C) The Author(s) 2020 